\title{
Nominal Rigidities, Asset Returns, and Monetary Policy*
}

\author{
Erica X.N. $\mathrm{Li}^{\dagger}$ and Francisco Palomino $\ddagger$
}

June 16, 2014

\begin{abstract}
Asset-return implications of nominal price and wage rigidities are analyzed in general equilibrium. Nominal rigidities, combined with permanent productivity shocks, increase expected excess returns on production claims. This is mainly explained by consumption dynamics driven by rigidity-induced changes in employment and markups. An interest-rate monetary policy rule affects asset returns. Stronger (weaker) rule responses to inflation (output) increase expected excess returns. Policy shocks substantially increase asset-return volatility. Price rigidity heterogeneity produces cross-sectoral differences in expected returns. The model matches important macroeconomic moments and the Sharpe ratio of stock returns, but only captures a small fraction of the observed equity premium.
\end{abstract}

JEL Classification: D51, E44, E52, G12.

Keywords: General equilibrium, asset pricing, monetary policy, nominal rigidities, expected stock returns, cross-section of stock returns.

\footnotetext{
${ }^{*}$ This paper is a substantially revised version of a paper that previously circulated as "Monetary Policy Risk and the Cross-Section of Stock Returns." We thank Sugato Bhattacharyya, Robert Barsky, Frederico Belo, François Gourio, Burton Hollifield, Howard Kung, Kenneth Kuttner, Sam Malone, Monika Piazzesi, Richard Priestley, Matthew Shapiro, Adrian Verdelhan, Lu Zhang, and participants at the University of Michigan Finance and Macroeconomics Brown Bags, the North American Summer Meeting of the Econometric Society 2008, the European Central Bank and Bank of England Workshop, the Western Finance Association meetings 2009 and 2013, the NBER Summer Institute in Monetary Economics 2009, the European Finance Association meeting 2009, the Federal Reserve Bank of Kansas City, the University of California Berkeley, Banco de la República, Universidad de los Andes, the UNC-Duke Asset Pricing Meeting 2010 and the UBC Winter Finance Conference 2012 for helpful comments and suggestions.

${ }^{\dagger}$ Cheung Kong Graduate School of Business, Beijing, China, 100738; Tel: (86)10 85188888 exit 3075; E-mail: xnli@ckgsb.edu.cn; http://www.cheungkong-gsb.com/FacultyResearch/Faculty/Finance/EricaXNLi.aspx.

${ }^{\ddagger}$ Corresponding author. The University of Michigan, Ross School of Business, Ann Arbor, MI 48109; Tel: (734) 615-4178; E-mail: fpal@umich.edu; http://webuser.bus.umich.edu/fpal/.
} 


\section{Introduction}

Explaining both asset return and aggregate business cycle fluctuations in a unified framework remains an important challenge in financial economics. Standard real business cycle models imply a counterfactually low compensation for risk in asset returns, partly because production factors can be freely adjusted to reduce consumption risk. ${ }^{1}$ This has motivated the introduction of real frictions to these models, such as investment adjustment costs and imperfect factor mobility, ${ }^{2}$ to attenuate the households' ability to smooth consumption. In the spirit of the New Keynesian literature, we study a different friction in an equilibrium model, i.e., rigidities in nominal product prices and wages, to address (i) how these rigidities and monetary policy affect the valuation of production claims such as stocks, and (ii) how productivity and monetary policy shocks affect the return dynamics of these claims.

Exploring nominal rigidities for the analysis of asset returns is motivated first by ample evidence of their existence in United States data. For instance, Nakamura and Steinsson (2008) report a median duration of prices between 8 and 11 months, and Barattieri, Basu and Gottschalk (2014) suggest an average wage duration between 3 and 4 quarters. ${ }^{3}$ Second, models with nominal rigidities, such as Christiano, Eichenbaum and Evans (2005) and Smets and Wouters (2007), have become the workhorse model for macroeconomic and policy analysis in central banks. These models capture important business cycle dynamics and are widely used to understand how monetary policy affects the real economy. It is then of significant importance to examine the link between monetary policy and asset returns implied by these models. ${ }^{4}$

The main findings in the paper are as follows. First, nominal rigidities, in combination with persistent shocks to productivity growth, improve the model's ability to generate positive and sizable expected excess returns in production claims. Second, the quantitative impact of wage rigidities on the equity premium is significantly larger than the impact of price rigidities. Third, monetary policy shocks have a large contribution to asset return volatility, but a minor effect on expected excess returns. Fourth, monetary policy rules with a greater weight on interest rate smoothing, a greater responsiveness to inflation, or a lower responsiveness to output lead to larger expected excess returns. Fifth, differences in price rigidities translate into differences in expected returns across production sectors. These differences are determined by product elasticities of substitution within and across sectors. Finally, the model calibration implies an annualized equity premium of only one percent, and a minor effect of monetary policy rules on asset returns. As in many other equilibrium models, it reflects the significant difficulty to amplify macroeconomic risk and generate enough asset return volatility.

Our production economy model has four main ingredients. First, a representative household with Epstein and Zin (1989) recursive preferences over consumption and labor. Recursive preferences disentangle the elasticity of intertemporal substitution of consumption (EIS) from risk aversion. As illustrated by Tallarini (2000), this separation is useful to keep reasonable values for the elasticity of substitution to match macroeconomic dynamics, while having values for risk aversion that match empirical Sharpe ratios of financial assets. Second, nominal rigidities are modeled in a staggered wage and price setting following Calvo (1983). The representative household provides differentiated labor types to the production sector and has monopolistic power to set wages. However, at each point of time the household can only adjust wages optimally for a fraction of labor types. Similarly, firms provide differentiated products and have monopolistic power to set their prices. At each point of time, a firm can only adjust the price optimally with some positive probability. Third, monetary policy is modeled as a Taylor (1993) policy rule to set

\footnotetext{
${ }^{1}$ Campbell and Cochrane (1999) and Bansal and Yaron (2004), among others, have made significant progress in capturing asset pricing dynamics in endowment economies. These efforts are less successful in production economies as shown by Boldrin, Christiano and Fisher (2001) and Kaltenbrunner and Lochstoer (2010), respectively.

${ }^{2}$ See Boldrin, Christiano and Fisher (2001), for instance.

${ }^{3}$ Blinder et al. (1998) summarize theories for the existence of price rigidities based on the nature of costs, demand, contracts, market interactions, and imperfect information. Wage rigidities are linked to the nature of labor contracts, unions, and laws.

${ }^{4}$ Bond returns have been analyzed extensively in the New Keynesian framework. See for instance Bekaert, Cho and Moreno (2010), Rudebusch and Swanson (2008, 2012) and Palomino (2012). Stock returns have been less studied in this literature.
} 
the level of a nominal interest rate. The rule responds to current economic conditions and is affected by policy shocks. Fourth, the model incorporates permanent and transitory shocks to productivity. This shock specification is motivated by Campbell (1994), who shows that permanent and transitory shocks have different effects on optimal consumption and asset returns, and by the Alvarez and Jermann (2005) empirical evidence of a significant permanent component in the pricing kernel.

The model is calibrated to match relevant properties of quarterly U.S. data for the 1982-2008 period. Price and wage rigidity parameters are chosen to match the average duration of prices and wages in the data. Parameters describing shocks, preferences, and the monetary policy rule are calibrated to match consumption, inflation, and interest rate volatility. Risk aversion is set to match the Sharpe ratio implied by equity returns. The calibration implies an EIS of around 0.15 , and a coefficient of relative risk aversion of around 16.

In the calibration, permanent productivity shocks contribute more than $96 \%$ to the risk premia in output and profit claims. This occurs despite the fact that the volatilities of the three model shocks are of comparable order of magnitude. To understand why, the pricing kernel is decomposed into short- and long-run components. Permanent productivity shocks have persistent effects that drive both components in the same direction, generating a large price for this risk. On the contrary, transitory productivity and monetary policy shocks have mean-reverting effects that drive the short- and long-run components in opposite directions, reducing their prices of risk.

In the absence of nominal rigidities, permanent productivity shocks imply a negative equity premium if the EIS is lower than one, echoing the results in Bansal and Yaron (2004) and Kaltenbrunner and Lochstoer (2010). After a negative permanent shock, output decreases. A substitution effect reduces the demand for future output claims and, hence, lowers the price of these claims. A wealth effect raises the relative price of future consumption and, hence, the price of output claims. The wealth effect dominates if the EIS is less than one, and output claims have a negative expected excess return over the risk-free rate.

In the presence of nominal rigidities, permanent productivity shocks generate a positive equity premium if the EIS is lower than one. Output dynamics are affected by the rigidities through their effects on employment and production markups. After a negative permanent shock, wages remain higher than optimal due to wage rigidities, and prices do not adjust enough to compensate for higher labor costs due to price rigidities. Employment decreases, amplifying the negative effect of the shock on output. Over time, real wages adjust towards their optimal levels, translating into higher expected future output growth. A substitution effect leads to a higher demand for claims on future output and, hence, a higher price for these claims. A wealth effect reduces the relative price of future output and lowers the price of output claims. The wealth effect dominates if the EIS is lower than one, and returns on output claims become procyclical and embed a positive risk premium. Procyclical product markups induced by the rigidities further amplify the volatility of dividend claims relative to output claims, increasing the equity premium.

Monetary policy is not neutral under nominal rigidities. The model calibration implies that a 50 -basispoint increase in the annualized nominal interest rate leads to a 62-basis-point decrease in equity returns, implying a positive equity premium. This premium is affected by the monetary policy rule. Rules with a higher responsiveness to inflation, lower responsiveness to output, or greater weight on interest-rate smoothing amplify the effects of permanent productivity shocks and increase expected excess returns. These results are explained by the effects of the rule on the real interest rate. However, monetary policy shocks have a small price of risk, only contribute with $1.5 \%$ of the total equity premium, and changes in risk premia from variations in the monetary policy rule parameters are quantitatively small.

A model extension to incorporate two production sectors allows us to explore the asset return implications of different price rigidities across sectors. Differences in the returns of claims on sectoral profits are driven by the difference in product prices (relative price) induced by the heterogeneous price rigidities. A high relative price for one sector leads to two opposite effects: lower profits due to lower output demand, and higher profits due to a higher production markup. The elasticity of substitution of products across sectors determines the difference in sectoral output demands. The elasticity of substitution of products within each sector determines the difference in sectoral markups. Depending on the difference between 
the two elasticities, the sector with higher price rigidities could earn higher or lower expected returns than the sector with lower price rigidities.

The contribution of the paper can be evaluated in three different dimensions. First, it shows that employment dynamics can play an important role in shaping risk premia. This channel can complement the investment channel already explored in the literature. Second, it links nominal rigidities to asset returns. This link can be important to understand the transmission channels of monetary policy. Third, it studies the effects of multiple shocks on asset prices in a calibrated framework. Asset returns can reflect compensations for shocks different than productivity shocks, that are important for macroeconomic dynamics. Quantitatively, nominal rigidities and permanent productivity shocks increase the equity premium relative to comparable real business cycle models. However, the model only generates one seventh of the observed equity premium, and the effects of monetary policy on asset returns are small. Despite this limitation, the model provides a reference point for asset-pricing New Keynesian models. Other elements such as additional frictions or shocks can be added to improve its quantitative performance.

This paper joins the literature that links the real economy to asset prices in a unified framework, ${ }^{5}$ such as Kaltenbrunner and Lochstoer (2010), Croce (2014), and Gourio (2012). It is mostly related to Boldrin, Christiano and Fisher (2001) and Christiano, Eichenbaum and Evans (2005). Boldrin, Christiano and Fisher (2001) show that adding frictions in intersectoral factor mobility and habit formation in preferences to the standard business cycle model of Kydland and Prescott (1982) reproduces important business cycle and equity return properties, simultaneously. However, habit formation also leads to a counterfactually high volatility in the risk-free rate. Our model instead relies on Epstein and Zin (1989) recursive preferences and permanent productivity shocks to achieve both a high price of risk and low volatility in the risk-free rate. As in the standard New Keynesian framework, described in Woodford (2003) and explored by Christiano, Eichenbaum and Evans (2005), frictions in the model result from nominal price and wage rigidities. While Christiano, Eichenbaum and Evans (2005) focus on their business cycle implications, this paper analyzes the effects of these frictions on asset prices.

The paper also is related to empirical studies on the response of the stock market to monetary policy shocks, such as Thorbecke (1997), Rigobon and Sack (2004), and Bernanke and Kuttner (2005), among others. Consistent with these studies, our model reproduces the positive (negative) response in the stock market value to expansionary (contractionary) policy shocks. However, this response in the model calibration is only one quarter of the one found empirically.

Recent efforts to understand the effects of labor and its frictions on asset returns are related to this paper. Lettau and Uhlig (2000) find that labor negatively affects the performance of habit models to capture the equity premium. This performance can be improved by adding real wage rigidities as shown by Uhlig (2007). In the same spirit, Favilukis and Lin (2013) analyze different asset return quantitative implications of infrequent renegotiation of real wages. This paper explores nominal instead of real wage rigidities, and time-varying instead of fixed employment, to understand their effects on asset returns.

A particular channel linking monetary policy to asset returns, i.e., monetary policy interest rate rules through nominal rigidities, is studied in this paper. Other channels have been explored theoretically or found empirically. For instance, Bhamra, Fisher and Kuehn (2011) provide an alternative channel for monetary policy to affect the real economy based on nominal rigidities in debt obligations. Lucca and Moench (2013) find robust evidence of a significant stock return during the 24-hour period before the FOMC meeting. This evidence suggests a puzzling strong link between asset returns and monetary policy difficult to study in equilibrium models.

The paper is organized as follows. Sections 2 and 3 present the model, its calibration and main implications. Sections 4 and 5 explain the mechanisms linking asset returns to nominal rigidities and monetary policy rules, respectively. Section 6 summarizes some cross-sectional implications and section 7 concludes.

\footnotetext{
${ }^{5}$ Cochrane (2006) provides an extensive summary of the main findings and challenges in this literature.
} 


\section{The Model}

We model a production economy where households derive utility from the consumption of a basket of differentiated goods and disutility from supplying a basket of differentiated labor services for the production of these goods. The differentiated goods are produced in an environment characterized by monopolistic competition and nominal price and wage rigidities. If some producers are not able to adjust prices optimally and/or if households are not able to adjust their wages optimally, inflation generates distortions in relative prices and/or real wages that affect production decisions. Since inflation is determined by monetary policy, different policies have different implications for real activity, affecting the returns on financial claims linked to production (e.g., stocks). Monetary policy is an interest-rate policy rule that reacts to inflation and deviations of output from a target. Productivity and monetary policy shocks are the sources of risk in the economy. Most model elements are standard in the New Keynesian literature with three exceptions. First, recursive preferences to increase risk aversion without affecting the elasticity of intertemporal substitution. This approach also has been used by Rudebusch and Swanson (2012). Second, transitory and permanent components in productivity shocks to identify their respective contributions to risk premia. Third, a model solution using second-order approximations of the optimality conditions to capture risk premia in expected asset returns.

\section{$2.1 \quad$ Household}

The representative household in this economy chooses consumption $C_{t}$ and labor supply $N_{t}^{s}$ to maximize the Epstein and Zin (1989) recursive utility function

$$
V_{t}=(1-\beta) U\left(C_{t}, N_{t}^{s}\right)^{1-\psi}+\beta \mathbb{E}_{t}\left[V_{t+1}^{\frac{1-\gamma}{1-\psi}}\right]^{\frac{1-\psi}{1-\gamma}},
$$

where $\beta>0$ is the subjective discount factor, $\psi^{-1}>0$ is the elasticity of intertemporal substitution of the utility aggregator of consumption and labor, and $\gamma>0$ determines the coefficient of relative risk aversion. The recursive utility formulation allows us to relax the strong assumption of $\gamma=\psi$ implied by constant relative risk aversion. The intratemporal utility is

$$
U\left(C_{t}, N_{t}^{s}\right)=\left(\frac{C_{t}^{1-\psi}}{1-\psi}-\kappa_{t} \frac{\left(N_{t}^{s}\right)^{1+\omega}}{1+\omega}\right)^{\frac{1}{1-\psi}},
$$

where $\omega^{-1}>0$ captures the Frisch elasticity of labor supply. The process $\kappa_{t}$, defined in section 2.2 , is introduced to preserve balanced growth. The consumption good is a basket of differentiated goods produced by a continuum of firms, defined as the Dixit-Stiglitz aggregator

$$
C_{t}=\left[\int_{0}^{1} C_{t}(j)^{\frac{\theta_{p}-1}{\theta_{p}}} d j\right]^{\frac{\theta_{p}}{\theta_{p}-1}}
$$

where $\theta_{p}>1$ is the elasticity of substitution across differentiated goods, and $C_{t}(j)$ is the consumption of the intermediate good $j$. As shown in appendix A, household's utility maximization leads to the demand function for intermediate goods $j^{6}$

$$
C_{t}(j)=\left(\frac{P_{t}(j)}{P_{t}}\right)^{-\theta_{p}} C_{t}
$$

where $P_{t}$ is the price of the final consumption good and $P_{t}(j)$ is the price of intermediate goods $j$.

Following Schmitt-Grohe and Uribe (2007), we assume that the representative household provides a

\footnotetext{
${ }^{6}$ Appendices can be found as part of the online supplemental material, or in the working paper version on the authors' websites.
} 
continuum of differentiated labor services indexed by $k \in[0,1]$. The aggregate supply of labor is

$$
N_{t}^{s}=\int_{0}^{1} N_{t}^{s}(k) d k
$$

where $N_{t}^{s}(k)$ is the supply of labor type $k .^{7}$

The representative household is subject to the intertemporal (nominal) budget constraint

$$
\mathbb{E}_{t}\left[\sum_{s=0}^{\infty} M_{t, t+s}^{\$} P_{t+s} C_{t+s}\right] \leq \mathbb{E}_{t}\left[\sum_{s=0}^{\infty} M_{t, t+s}^{\$} P_{t+s}\left(L I_{t+s}+D_{t+s}+\varphi_{t+s}\right)\right],
$$

where $M_{t, t+s}^{\$}$ is the nominal discount factor for cash flows at time $t+s$. The real labor income from supplying labor to the production sector is

$$
L I_{t}=\int_{0}^{1} \frac{W_{t}(k)}{P_{t}} N_{t}^{s}(k) d k
$$

where $W_{t}(k)$ is the wage of labor type $k$. The household owns the production sector and receives aggregate real dividends (profits) $D_{t} .{ }^{8}$ The last term in the budget constraint is the aggregate operation cost incurred during production, $\varphi_{t}$. Its detailed discussion will be given in section 2.2 .

Appendix A shows, from the household's optimality conditions, that the one-period real and nominal discount factors are the marginal rates of substitution

$$
M_{t, t+1}=\beta\left(\frac{C_{t+1}}{C_{t}}\right)^{-\psi}\left(\frac{V_{t+1}}{\mathbb{E}_{t}\left[V_{t+1}^{1-\gamma}\right]^{1 /(1-\gamma)}}\right)^{\psi-\gamma}, \quad \text { and } \quad M_{t, t+1}^{\$}=M_{t, t+1}\left(\frac{P_{t+1}}{P_{t}}\right)^{-1}
$$

respectively. The real and nominal discount factor gives us the one-period (continuously compounded) real nominal interest rates, characterized, respectively, as

$$
r_{t}=-\log \mathbb{E}_{t}\left[M_{t, t+1}\right], \quad \text { and } \quad i_{t}=-\log \mathbb{E}_{t}\left[M_{t, t+1}^{\$}\right] .
$$

\subsubsection{Wage Setting}

The labor market is imperfectly competitive. The representative household monopolistically provides the continuum of differentiate labor services described by equation (5). These labor services produce the homogeneous labor service used by the production sector, $N_{t}^{d}$, given by

$$
N_{t}^{d}=\left[\int_{0}^{1} N_{t}^{s}(k)^{\frac{\theta_{w}-1}{\theta_{w}}} d k\right]^{\frac{\theta_{w}}{\theta_{w}-1}}
$$

where $\theta_{w}>1$ is the elasticity of substitution across differentiated labor types. Appendix A shows that the optimal demand for labor type $k$ is

$$
N_{t}^{s}(k)=\left(\frac{W_{t}(k)}{W_{t}}\right)^{-\theta_{w}} N_{t}^{d}
$$

\footnotetext{
${ }^{7}$ This approach is different from the standard heterogeneous households approach to model wage rigidities in Erceg, Henderson and Levin (2000), where each household supplies a differentiated type of labor. In the presence of recursive preferences, this approach introduces heterogeneity in the marginal rate of substitution of consumption across households since it depends on the labor types supplied by households. We avoid this difficulty and obtain a unique marginal rate of substitution by modeling a representative agent who provides all different types of labor.

${ }^{8}$ It is assumed that the household does not participate in managing the production activity. In reality, individuals own firms through diffused ownership and collectively hire professional managers to run firms for them.
} 
and the aggregate wage is

$$
W_{t}=\left[\int_{0}^{1} W_{t}^{1-\theta_{w}}(k) d k\right]^{\frac{1}{1-\theta_{w}}}
$$

Note that $N_{t}^{s}$ refers to the aggregate supply of all labor types, while $N_{t}^{d}$ refers to the homogeneous labor service demanded by the production sector. The household chooses wages $W_{t}(k)$ for all labor types $k$ under Calvo (1983) staggered wage setting. Specifically, at each time $t$ the household adjusts wages optimally only for a fraction $1-\alpha_{w}$ of random labor types. For the remaining fraction $\alpha_{w}$, the household keeps the previous period wages $W_{t-1}(k)$. Since the demand curve and the cost of labor supply are identical across different labor types, the optimal nominal wage of labor type $k, W_{t}^{*}(k)$, is the same for all labor types $k \in[0,1]$, denoted as $W_{t}^{*}$. The appendix shows that the optimal wage satisfies

$$
\frac{W_{t}^{*}}{P_{t}}=\mu_{w, t} \kappa_{t}\left(N_{t}^{s}\right)^{\omega} C_{t}^{\psi}
$$

where $\mu_{w, t}$ is the time-varying wage markup (described in the appendix). Equation (13) can be interpreted as follows: in the absence of wage rigidities $\left(\alpha_{\omega}=0\right)$, the marginal rate of substitution between labor and consumption is $\kappa_{t}\left(N_{t}^{s}\right)^{\omega} C_{t}^{\psi}$, and the optimal wage is this rate adjusted by the optimal constant markup $\mu_{w}=\theta_{w} /\left(\theta_{w}-1\right)$. Wage rigidities generate a time-varying wage markup $\mu_{w, t}$, since the wage of some labor types is not adjusted optimally.

\subsection{Production Sector}

The production of differentiated goods is characterized by monopolistic competition and price rigidities in a continuum of firms. Firms, indexed by $j$, take wages as given and set prices for their differentiated goods in a Calvo (1983) staggered price setting: at each time $t$, a fraction $\alpha_{p}$ of random firms keep their previous period prices $P_{t-1}(j)$, while the remaining fraction $1-\alpha_{p}$ set prices to maximize the present value of their profits. A firm maximizing profits takes into account the probability $\alpha_{p}$ of not being able to adjust the price optimally in the future. Specifically, firm $j$ solves the maximization problem

$$
\max _{\left\{P_{t}(j)\right\}} \mathbb{E}_{t}\left\{\sum_{s=0}^{\infty} \alpha_{p}^{s} M_{t, t+s}^{\$}\left[P_{t}(j) Y_{t+s \mid t}(j)-W_{t+s \mid t} N_{t+s \mid t}^{d}(j)-\varphi_{t+s}\right]\right\},
$$

subject to the demand function

$$
Y_{t+s \mid t}(j)=\left(\frac{P_{t}(j)}{P_{t+s}}\right)^{-\theta_{p}} Y_{t+s}
$$

and the production function

$$
Y_{t+s \mid t}(j)=A_{t+s} N_{t+s \mid t}^{d}(j) .
$$

Output $Y_{t+s \mid t}(j)$ is the production of firm $j$ at time $t+s$ given that its last optimal price change was at time $t$. The wage $W_{t+s \mid t}$ and the firm's demand $N_{t+s \mid t}^{d}(j)$ of homogeneous labor service have a similar interpretation. The functional form of the demand function is identical to the demand function for consumption in equation (4).

The production function depends on labor productivity $A_{t}$ and labor. We assume that labor productivity contains permanent and transitory components. Specifically, $A_{t}=A_{t}^{p} Z_{t}$, where the permanent and transitory components follow processes

$$
\Delta \log A_{t+1}^{p}=\phi_{a} \Delta \log A_{t}^{p}+\sigma_{a} \varepsilon_{a, t+1},
$$


and

$$
\log Z_{t+1}=\phi_{z} \log Z_{t}+\sigma_{z} \varepsilon_{z, t+1},
$$

respectively, with $\Delta$ as the difference operator, and innovations $\varepsilon_{a, t}$ and $\varepsilon_{z, t} \sim \operatorname{IID} \mathcal{N}(0,1)$. Given the permanent component in productivity, the operation cost is defined as $\varphi_{t} \equiv A_{t}^{p} \bar{\varphi}$. Under this definition, the operation cost is fixed $(\bar{\varphi})$ relative to the balanced growth path. The cost is paid by producers to the household as presented in the budget constraint (6). An example of this cost is rental of office space owned by households. Similarly, the scaling process $\kappa_{t}$ in the utility function $(2)$ is defined as $\kappa_{t} \equiv\left(A_{t}^{p}\right)^{1-\psi}$ to preserve balanced growth.

All firms that set prices optimally face and identical maximization problem and then choose the same optimal price $P_{t}^{*}$ when allowed. Appendix B shows that the optimal price satisfies

$$
\left(\frac{P_{t}^{*}}{P_{t}}\right)=\frac{\mu_{p, t}}{A_{t}} \frac{W_{t}}{P_{t}}
$$

where $\mu_{p, t}$ is the time-varying product markup (described in the appendix). Equation (19) can be interpreted as follows: In the absence of price rigidities, the product price is the markup-adjusted marginal cost of production, with optimal markup $\mu_{p}=\theta_{p} /\left(\theta_{p}-1\right)$. Price rigidities generate the time-varying markup $\mu_{p, t}$, since some firms do not adjust their prices optimally.

\subsection{Monetary Policy}

The monetary authority sets the level of the one-period nominal interest rate $i_{t}$. Monetary policy is described by the policy rule

$$
i_{t}=\rho i_{t-1}+(1-\rho)\left(\bar{\imath}+\imath_{\pi} \pi_{t}+\imath_{x} x_{t}\right)+u_{t},
$$

where the interest rate is set responding to the lagged interest rate, aggregate inflation $\pi_{t} \equiv \log P_{t}-$ $\log P_{t-1}$, the output gap $x_{t}$, and a policy shock $u_{t}$. The output gap is defined as

$$
x_{t} \equiv \log Y_{t}-\log Y_{t}^{f}
$$

where $Y_{t}^{f}$ is the output under perfectly flexible prices and wages, defined in appendix D. The policy shock follows the process

$$
u_{t+1}=\phi_{u} u_{t}+\sigma_{u} \varepsilon_{u, t+1}
$$

with $\varepsilon_{u} \sim \operatorname{IIDN}(0,1)$.

\subsection{Asset Returns}

The real price of a claim on all future cash flows $\left\{B_{t+s}\right\}_{s=1}^{\infty}$ is

$$
S_{B, t}=\mathbb{E}_{t}\left[\sum_{s=1}^{\infty} M_{t, t+s} B_{t+s}\right] .
$$

The one-period real return of this claim is

$$
R_{B, t+1}=\frac{B_{t+1}+S_{B, t+1}}{S_{B, t}}=\frac{B_{t+1}}{B_{t}}\left(\frac{1+P_{B, t+1}}{P_{B, t}}\right),
$$

where $P_{B, t}$ is the price-cash flow ratio, defined as $P_{B, t} \equiv \frac{S_{B, t}}{B_{t}}$. 
We analyze expected returns for claims on aggregate output $(B=Y)$ and dividends $(B=D)$. Appendix $\mathrm{F}$ derives the approximate decomposition for the expected excess return

$$
\log \mathbb{E}_{t}\left[R_{B, t+1}\right]-\log R_{f, t}=-\operatorname{cov}_{t}\left(m_{t, t+1}, \Delta b_{t+1}\right)-\operatorname{cov}_{t}\left(m_{t, t+1}, \log \left(1+P_{B, t+1}\right)\right),
$$

where $R_{f, t}$ is the one-period real risk-free rate satisfying $\left(1+R_{f, t}\right)^{-1}=\mathbb{E}_{t}\left[M_{t, t+1}\right], m_{t, t+1} \equiv \log M_{t, t+1}$, and $b_{t} \equiv \log B_{t}$. We use this decomposition for the analysis.

\subsection{Equilibrium}

The equilibrium of the economy requires product, labor, and financial market clearing. Product market clearing requires that consumption equals production, i.e., $C_{t}=Y_{t}$. Labor market clearing requires that the supply and demand of labor type $k$ to produce good $j$ are equal for all $k$ and $j$. Financial market clearing requires the nominal interest rate from the household's problem in equation (9) to match the interest rate set by the monetary authority, i.e.,

$$
-\log \mathbb{E}\left[M_{t, t+1}^{\$}\right]=\rho i_{t-1}+(1-\rho)\left(\bar{\imath}+\imath_{\pi} \pi_{t}+\imath_{x} x_{t}\right)+u_{t} .
$$

Appendix D provides a summary of the system of equations describing the equilibrium of the model. We find the equilibrium numerically, using a second-order approximation of the optimality conditions. ${ }^{9} \mathrm{~A}$ second-order approximation is required to capture non-zero expected excess returns on financial claims. This solution method, however, does not allow us to explore time variation in expected excess asset returns. Expected excess returns are constant up to a second-order approximation.

\section{Calibration and Model Implications}

We analyze the implications of nominal rigidities and monetary policy on expected asset returns of production claims, focusing on claims on all future output and profits. The effects of nominal rigidities on expected excess returns can be understood by the impact of these rigidities on the pricing kernel, output, labor, and production markups. The model is calibrated to capture important dynamics of United States macroeconomic variables and stock returns. Different model specifications are compared to highlight the most important channels driving the results.

\subsection{Calibration}

The calibration matches properties of quarterly U.S. data from 1982:1 to 2008:3 for consumption, inflation, the short-term nominal interest rate, and stock returns. This period is chosen to avoid changes in the monetary policy regime, as suggested by Clarida, Galí and Gertler (2000). ${ }^{10}$ The consumption series was constructed using data on real consumption of nondurables and services from the Bureau of Economic Analysis. The series is de-trended using the Hodrick-Prescott filter. The inflation series was constructed to capture inflation related only to consumption of non-durables and services, following the methodology in Piazzesi and Schneider (2007). The short-term nominal rate is the 3-month T-bill rate from the Fama risk-free rates database. The stock market data are the quarterly returns of the market portfolio obtained from the Center for Research in Security Prices (CRSP).

Table 1 presents the parameter values for the baseline calibration. The constant growth rate of the permanent productivity shock $g_{a}$ is chosen to match the growth rate of consumption for the sample period. The value of $\theta_{p}$ is chosen to obtain an average production markup of $20 \%$. This is the value for the "high markup" specification in Altig et al. (2011) (hereafter ACEL). The price rigidity parameter

\footnotetext{
${ }^{9}$ We use the Dynare package available from www.dynare.org to solve the model.

${ }^{10}$ We do not include data after 2008:3 since the financial crisis drove short-term interest rates to the zero bound. For the most recent period after 2008, monetary policy is better described by unconventional tools, such as quantitative easing, rather than by an interest-rate rule.
} 
value $\alpha_{p}$ is chosen such that the average price duration is 2.2 quarters, consistent with the empirical evidence in Bils and Klenow (2004). The value of $\theta_{w}$ is such that the average wage markup is $5 \%$. The wage rigidity parameter $\alpha_{w}$ implies a duration of wages of four quarters, as estimated in ACEL. The parameter $\beta$ (and $\bar{\imath}=-\log (\beta)+\psi g_{a}$ ) is chosen to match the average level of the nominal risk-free rate. This value implies a growth adjusted subjective discount factor of $\beta e^{-\psi g_{a}}=0.975$. The interest rate rule parameters $\rho, \imath_{\pi}$, and $\imath_{x}$ are chosen to be consistent with the evidence for the sample period according to Clarida, Galí and Gertler (2000).

The parameter values for the elasticities $\psi, \omega$, and the autocorrelations and conditional volatilities of productivity and policy shocks are chosen to match the variance decompositions of (de-trended) consumption, inflation and the short-term nominal interest rate presented in ACEL. ACEL use a VAR to identify productivity and policy shocks and obtain a variance decomposition for different macroeconomic variables. Table 2 presents their variance decomposition for inflation, consumption and the short-term interest rate. ${ }^{11}$ Productivity and policy shocks explain a small fraction of the total volatility of the three macroeconomic variables. Based on this decomposition, parameter values are chosen to match the contribution of these shocks to the total variability of the macroeconomic series. Since the model has both permanent and transitory components in productivity, additional restrictions are required to identify the variability explained by each of these components. We choose a mix of shocks that matches the volatility of consumption growth. Specifically, a calibration in which productivity has only a permanent component implies a volatility of consumption growth significantly higher than in the data. On the other hand, a calibration where productivity has only a transitory component implies a very low volatility in consumption growth. The combination of permanent and transitory productivity shocks with policy shocks matches the volatility of consumption growth in the data. ${ }^{12}$ A significant fraction of this volatility is attributed to permanent shocks.

Table 2 shows that the model is able to match the contributions of productivity and policy shocks to the total variability of de-trended consumption, inflation, and the nominal interest rate. The calibration implies a low elasticity of intertemporal substitution of $1 / 6.5 \approx 0.15$, and a Frisch elasticity of labor supply of $1 / 0.35 \approx 2.86 .^{13}$

Finally, the fixed operation cost $\bar{\varphi}$ is set to match the volatility of dividend growth of the aggregate stock market, and $\gamma$ to match the stock market quarterly Sharpe ratio, as in Tallarini (2000) and Kaltenbrunner and Lochstoer (2010). Consistent with the empirical practice, the nominal risk-free rate and expected asset returns are used to calculate the model implied Sharpe ratio.

The recursive utility specification is critical for the model to match the Sharpe ratio. As in Tallarini (2000), the macroeconomic properties of the model depend on the elasticity of substitution but are not significantly affected by risk aversion. The parameter $\gamma$ is set at 84.5. In the presence of leisure preferences, the household's attitude toward risk is not only determined by this parameter but also by the willingness to supply labor in different states of the world. As shown by Swanson (2012), the (average) coefficient of relative risk aversion for the recursive preferences in equation (1) is

$$
\frac{\psi}{1+\frac{\psi \mu_{w}}{\omega \mu_{p}}}+\frac{\gamma-\psi}{1-\frac{1-\psi}{1+\omega}} \approx 16
$$

This value is still high according to empirical and experimental evidence, ${ }^{14}$ but significantly lower than

\footnotetext{
${ }^{11}$ ACEL refers to these productivity shocks as "neutral technology" shocks. The variance decomposition in ACEL for the short-term rate refers to the Federal Funds rate. We assume that the same variance decomposition applies to the three-month T-bill rate. ACEL estimate their VAR using data for 1982-2008, consistent with our sample period.

${ }^{12}$ Ideally, we should match the volatility of consumption growth explained by productivity and policy shocks. However, we match the total volatility of consumption growth to make a more meaningful comparison with other asset pricing models.

${ }^{13}$ Macroeconomic models usually rely on elasticities of substitution between 0 and 1 . The Bansal and Yaron (2004) model requires an elasticity of substitution greater than 1 in order to capture the observed equity premium. Empirical estimates are below and above 1. For instance, Hall (1988) provides an estimate very close to zero, and Vissing-Jorgensen (2002) finds an elasticity for stockholders around 0.3 to 0.4 ., and very close to zero for non-stockholders. On the other hand, Vissing-Jorgensen and Attanasio (2003) conclude that the elasticity for stockholders is likely to be above 1.

${ }^{14}$ See, for instance, Barsky et al. (1997).
} 
the values required by standard real business cycle models to match Sharpe ratios. For instance, Tallarini (2000) requires a risk aversion coefficient of around 1,000 .

\subsection{Quantitative results}

We explain in this section the three main implications for asset returns of the model calibration. First, expected excess returns on production claims are mainly a compensation for shocks to the permanent component of productivity. Table 3 presents summary statistics for the baseline calibration along with those from alternative model specifications. Column (1) shows that the quarterly expected excess returns on output and profit claims are 12 and $24 \mathrm{bps}$, respectively, in the baseline calibration. Claims on profits are riskier than claims on output as a result of a procyclical production markup, $\rho(\Delta c, \log \mu)>0$, and the fixed operation cost, $\bar{\varphi}>0$. Fixed operation costs add a leverage effect that amplifies the magnitude and risk of returns on profit claims. In an economy with no fixed production costs $(\bar{\varphi}=0)$, the expected excess return on the profit claim is 13 bps. The procyclical markup is the result of price rigidities (in combination with wage rigidities). Profits are riskier than output because profits decline by more than output when marginal utility is high, as a result of lower markups (product prices are low relative to marginal costs).

Columns (2) to (4) in the table allow us to quantify the individual contributions of the three model shocks to the results. Each column corresponds to the baseline calibration with only one shock in the economy (the volatility of the two other shocks is set to zero). It is clear from the table that expected excess returns are mostly a compensation for permanent productivity shocks. These shocks contribute around 12 and 23 bps to the premium in output and profit claims, respectively. The total contribution of transitory productivity and policy shocks is less than one basis point. The difference is also reflected in the implied Sharpe ratios. The Sharpe ratio for permanent shocks is significantly higher than the Sharpe ratios for the other two shocks: 0.28 for permanent shocks in profit claims compared to 0.01 for transitory productivity and policy shocks. The significant difference in the contributions of these shocks is explained in section 4 .

The second finding is that both price and wage rigidities increase expected excess returns on output and profit claims, but wage rigidities have a significantly larger impact than price rigidities. Table 4 allows us to make comparisons of the baseline model with model specifications with no rigidities, or only wage or price rigidities. ${ }^{15}$ The economy with no rigidities in column (2) can be seen as a frictionless real business cycle economy. In the absence of nominal rigidities, the model implies negative expected excess returns on both output and profit claims. Once wage rigidities or price rigidities are introduced, columns (3) and (4), respectively, show that expected excess returns on these claims become positive. It can be seen that wage rigidities generate larger expected excess returns than price rigidities. This can be explained by the significant response of employment to permanent productivity shocks under wage rigidities, as shown in section 4 . It is worth noting in column (3) that claims on output and profits have the same expected returns since markups are constant when prices are flexible. On the other hand, column (4) shows that profit claims are less risky than output claims in a model with only price rigidities.

The third finding is that the magnitude of the equity premium implied by the model is very small in comparison to its empirical counterpart. Table 3 shows that the expected excess return on profit claims is 24 bps per quarter in the baseline calibration. This represents a small fraction of the equity premium of $1.78 \%$ per quarter in the data. Since the calibration matches the empirical Sharpe ratio, the result implies that the volatility of profit claim returns in the model is too low. It occurs despite the fact that the calibration matches the volatility of dividend growth in the data. This leads us to conclude that the traditional model with nominal rigidities has a significant limitation to translate macroeconomic volatility into asset return volatility. We address this shortcoming, provide an interpretation, and suggest

\footnotetext{
${ }^{15}$ For this comparison, the fixed operation $\operatorname{cost} \bar{\varphi}$ is set to zero. This simplification allows a clean comparison across models for returns on profit claims, and does not alter the qualitative properties of the model. Specifically, the fixed operation cost value was chosen in the baseline model to match the volatility of aggregate dividends. This value implies and implausibly high dividend growth volatility in the specification with only price rigidities that obscures the interpretation of the results.
} 
potential improvements for the model in section 7 .

\section{Understanding the Mechanism}

This section explains why expected excess returns on production claims are amplified by nominal rigidities, mainly as a compensation for permanent productivity shocks.

\subsection{Role of permanent productivity shocks}

Permanent productivity shocks have the largest contribution to the volatility of the pricing kernel in equation (8). To understand why, appendix E shows that the log-pricing kernel can be decomposed as

$$
m_{t, t+1}=\vartheta \log \beta+m_{t, t+1}^{S R}+m_{t, t+1}^{L R},
$$

where

$$
m_{t, t+1}^{S R}=-\psi \vartheta \Delta c_{t+1}-(1-\vartheta) \Delta q_{t+1}, \quad \text { and } \quad m_{t, t+1}^{L R}=-(1-\vartheta) \log \left(\frac{1+P_{Q, t+1}}{P_{Q, t}}\right)
$$

are the short- and long-run components, respectively, and $\vartheta \equiv(1-\gamma) /(1-\psi) . P_{Q, t}$ is the price-cash flow ratio for the claim on all future cash flows $\left\{Q_{t+s}\right\}_{s=0}^{\infty}$, and $q_{t} \equiv \log Q_{t}$. This claim is the wealth portfolio in the economy, with cash flows $Q_{t}$ that are combination of consumption and labor income, as defined in the appendix. The dependence on labor income results from labor preferences. In the absence of these preferences, $Q_{t}=C_{t}$, and the wealth portfolio becomes a claim on future consumption. The short-run component $m^{S R}$ contains shocks to current period consumption and labor income growth, while the longrun component $m^{L R}$ contains shocks to the return on wealth. In Bansal and Yaron (2004) and Croce (2014), the short- and long-run components are uncorrelated by design. In this model economy, and similar to Kaltenbrunner and Lochstoer (2010), innovations to the short- and long-run components come from the same shocks and, hence, are correlated. Productivity and monetary policy shocks contribute to both components. Therefore, not only the volatility of these components but also their correlation are important to determine the volatility of the pricing kernel and the prices of risk.

Panel $\mathrm{C}$ in table 4 shows that the volatility of the pricing kernel from permanent shocks is five times larger than that from transitory shocks, and seventy times larger than that from monetary policy shocks. However, the contributions of these shocks to the volatilities of the short- and long-run components of the pricing kernel are of similar magnitude. The large difference in the volatility of the pricing kernel is mainly driven by the correlation between $m^{S R}$ and $m^{L R}$. This correlation is positive under permanent productivity shocks, but negative under transitory productivity and monetary policy shocks. After a permanent productivity shock, both current and future consumption (and labor income) decrease, and then generate a positive correlation between $m^{S R}$ and $m^{L R}$ and a large volatility of the pricing kernel. On the other hand, since both transitory productivity and monetary policy shocks are mean-reverting, bad news for current consumption (labor income) means good news for future consumption (labor income). Consequently, the correlation between $m^{S R}$ and $m^{L R}$ generated by these shocks is negative, and their contribution to the volatility of the pricing kernel is small.

\subsection{Role of nominal rigidities}

Nominal rigidities affect returns on production claims through their effects on output dynamics and the marginal utility of consumption. These effects, in turn, can be understood from employment and product markup dynamics. To highlight the main mechanisms, an economy affected only by permanent productivity shocks and no fixed operation costs $(\bar{\varphi}=0)$ is analyzed. Permanent productivity shocks are the quantitatively important source of risk premia, as shown above. Fixed costs in the model always amplify the volatility of dividends relative to output and, hence, the absolute value of the risk premium 
in dividend claims relative to output claims. For comparison purposes, we describe first the properties of expected excess returns in an economy with no rigidities.

\subsubsection{Asset returns under flexible prices and wages}

Table 3 shows that expected asset returns are negative in an economy with no rigidities. ${ }^{16}$ Employment and production markups are constant in this economy. Profits are then a constant fraction of output, and expected returns on output and profit claims are the same. Consider the expected excess return decomposition in equation (25) for the output claim. The first term in the equation generates a positive premium because a negative shock leads to a higher marginal rate of substitution of consumption and lower output. However, the second term generates a negative premium that is larger than the first term. The second term is negative since the negative shock leads to a higher price-output ratio, $P_{Y, t+1}$. To understand why, appendix $\mathrm{G}$ shows that $P_{Y, t}$ is approximately given by

$$
\log P_{Y, t}=\text { const }+\frac{\phi_{a}(1-\psi)}{1-\kappa_{Y} \phi_{a}} \Delta a_{t}
$$

where the positive constant $\kappa_{Y}<1$ is defined in the appendix. Throughout the paper, "const" is used to refer to any unimportant constant for the analysis. It is clear that the sensitivity of $P_{Y, t}$ to the shock is negative when the inverse of the elasticity of substitution (EIS) $\psi$ is larger than one. Two opposite effects drive this result. First, a substitution effect: after a persistent negative shock, the household reduces the demand for the output claim to smooth consumption over time (lowers $P_{Y, t+1}$ ); and second, a wealth effect: the persistent shock signals lower future output which increases its relative price (raises $\left.P_{Y, t+1}\right)$. When the EIS is lower than one, the wealth effect dominates the substitution effect, making output claims a hedging instrument.

\subsubsection{Nominal rigidities and employment dynamics}

Employment becomes procyclical and mean reverting in the presence of nominal rigidities. This feature is critical in the model to generate positive expected excess returns. Appendix G shows that employment and the price-output ratio are approximated by

$$
\log N_{t}^{d}=\mathrm{const}+n_{a} \Delta a_{t}, \quad \text { and } \quad \log P_{Y, t}=\mathrm{const}+\frac{\left[\phi_{a}-\left(1-\phi_{a}\right) n_{a}\right](1-\psi)}{1-\kappa_{Y} \phi_{a}} \Delta a_{t},
$$

respectively. Procyclical labor demand, $n_{a}>0$, leads to a procyclical $P_{Y, t}$ and, hence, a positive expected excess return in output claims if $n_{a}$ is large enough. The economic intuition for a positive $n_{a}$ is as follows. Wage rigidities prevent nominal wages from adjusting downward after a negative productivity shock. Product prices remain high to preserve production markups, real production costs stay high, and labor demand declines. Similarly, price rigidities keep prices high after a negative productivity shock. Nominal wages stay high to preserve labor markups, and labor demand declines. Therefore, nominal rigidities lead to a procyclical labor demand that amplifies the effect of permanent productivity shocks on output. This effect, however, is mean reverting since prices and wages gradually adjust over time, increasing future labor demand after a negative shock. Strong mean reversion in labor demand, $n_{a}>\phi_{a} /\left(1-\phi_{a}\right)$, leads to a higher expected consumption growth after a negative shock, the substitution effect increases the demand for future output claims (raises $P_{Y, t}$ ), and the wealth effect reduces the price of future consumption (lowers $P_{Y, t}$ ). The wealth effect dominates if $\psi>1$, making output claims risky.

\footnotetext{
${ }^{16}$ This is a standard result in models with permanent productivity shocks and a lower than one EIS. See Bansal and Yaron (2004) for an endowment economy, and Croce (2014) and Kaltenbrunner and Lochstoer (2010) for production economies with fixed employment.
} 


\subsubsection{Price rigidities and time-varying markups}

Table 3 shows that output and profit claims have the same expected returns in models with no rigidities or with only wage rigidities. This is the result of a constant production markup. Producers freely adjust prices to keep their optimal markups. This is no longer true in the presence of price rigidities. In the baseline model with price and wage rigidities, markups are procyclical and expected returns on profit claims are higher than expected returns on output claims. Markups vary over time since some producers are unable to adjust prices to restore the optimal markup. ${ }^{17}$ They are procyclical since, given the rigidities, nominal wages react by less than prices in the calibration: after a negative shock, marginal costs remain high relative to product prices, decreasing production markups and amplifying the risk of profit claims relative to output claims.

\section{$5 \quad$ Interest Rate Policy Rule and Asset Returns}

This section describes how monetary policy shocks and the response to economic conditions in the interest rate rule (20) affect asset returns. In an economy with flexible prices and wages, the policy rule does not have any real effects: policy changes in the nominal interest rate are solely reflected in changes in inflation, and do not affect real interest rates and asset returns. That is, the interest rate rule does not affect (real) risk premia and return volatility.

\subsection{Policy shocks, asset volatility, and expected returns}

In the model economy with nominal rigidities, table 3 shows that policy shocks generate volatility in real asset returns and command a small positive compensation for risk. Figure 1 shows that an expansionary monetary policy shock leads to lower nominal and real interest rates. The real rate decreases since nominal prices and nominal wages do not fully adjust to neutralize the change in the nominal rate. ${ }^{18}$ Consequently, both output and dividends increase, the marginal utility of consumption decreases, and then the compensation for policy shocks in expected returns on output and dividend claims is positive. The compensation is small, however, as the volatility in the pricing kernel induced by policy shocks is small.

Bernanke and Kuttner (2005) show that an unanticipated 25-basis-point cut in the federal funds rate is associated with about a 100-basis-point increase in a broad stock market index. This evidence is qualitatively captured by the model but with a smaller magnitude. Figure 1 indicates that a 50-basispoint reduction in the annualized nominal interest rate leads to a 62-basis-point increase in the value of the dividend claim after a monetary policy shock.

\subsection{Response to economic conditions and asset returns}

Panel A of table 5 allows us to compare summary statics for the baseline model calibration and three "policy experiments". The experiments are individual changes in the responses to inflation $\left(l_{\pi}\right)$ and the output gap $\left(l_{x}\right)$, and the interest rate smoothing coefficient $(\rho)$ in the policy rule. Column (2) in the table shows that an increase of $\imath_{\pi}$ from 1.5 to 1.89 leads to a $10 \%$ drop in inflation volatility, and $9.82 \%$ (1.22 bps) and $3.47 \%$ (0.82 bps) increases in expected excess returns on output and dividend claims, respectively. After a negative permanent productivity shock, wage rigidities keep wages high and prices increase to compensate for the high labor costs. A stronger response to inflation in the rule leads to a higher real interest rate, which further lowers output and increases risk premia.

\footnotetext{
${ }^{17}$ In a model with only price rigidities, production markups are countercyclical and expected returns on profit claims are lower than expected returns on output claims. In both models, however, profits remain procyclical as observed in the data.

${ }^{18}$ There is also a feedback effect on nominal interest rate from contemporaneous changes in inflation and output caused by the monetary policy shock.
} 
Similarly, a reduced response to the output gap, $\imath_{x}$, reduces the response to productivity shocks of the real interest rate. A relatively higher real rate after a negative shock amplifies the negative effect on output of the shock. Therefore, risk premia are higher with a lower $\imath_{x}$. Quantitatively, column (3) in the table shows that a change in $\imath_{x}$ from 0.125 to -0.16 leads to a $10 \%$ increase in output gap volatility, and $16.48 \%$ (2.05 bps) and $3.94 \%$ (0.95 bps) increases in expected excess returns on output and dividend claims, respectively. ${ }^{19}$

Finally, stronger interest rate smoothing reduces the relative weight of the response to inflation and the output gap in the rule. Column (4) in the table shows that an increase in $\rho$ from 0.63 to 0.712 simultaneously increases inflation and output volatility. The $10 \%$ increase in output gap volatility translates into $6.38 \%$ (0.79 bps) and $0.83 \%(0.20 \mathrm{bps})$ increments in expected excess returns on output and dividend claims, respectively. It is worth noting that the model calibration implies a very small sensitivity of expected excess returns to variations in the policy rule.

\section{Price Rigidities and Cross-Sectoral Returns}

Bils and Klenow (2004) present evidence of significant dispersion of price stickiness across industries. Differences in the degree of price rigidity across industries may translate into differences in the expected returns of their production claims. To explore this channel, the model is extended to incorporate two sectors, $H$ and $L$, characterized by high and low price rigidities, $\alpha_{p_{H}}$ and $\alpha_{p_{L}}$, respectively. The two sectors are identical except for the degree of price rigidity. The consumption products of the two sectors, $C_{H, t}$ and $C_{L, t}$, respectively, conform the basket of consumption goods

$$
C_{t}=\left[\nu^{1 / \eta} C_{H, t}^{\frac{\eta-1}{\eta}}+(1-\nu)^{1 / \eta} C_{L, t}^{\frac{\eta-1}{\eta}}\right]^{\frac{\eta}{\eta-1}}, \quad \text { where } \quad C_{I, t}=\left[\int_{0}^{1} C_{I, t}(j)^{\frac{\theta_{p}-1}{\theta_{p}}} d j\right]^{\frac{\theta_{p}}{\theta_{p}-1}},
$$

for $I=\{H, L\}, \nu$ is the weight of sector $H$ in the basket, and $\eta>1$ is the elasticity of substitution between sectoral goods. Each production sector maximizes profits as in section 2, subject to the price rigidity $\alpha_{p_{I}}{ }^{20}$ Returns of output and profit claims, $R_{Y_{I}, t}$ and $R_{D_{I}, t}$, respectively, are compared across sectors. If $\alpha_{p_{H}}$ and $\alpha_{p_{L}}$ are the same, the two sectors are identical and share the same expected asset returns. If the price rigidities are different, the implications on the cross section of asset returns depend on elasticity parameters. To illustrate the main mechanism, consider the valuation of claims on sectoral profits that pay off only one-period in the future. Under the assumption of no fixed operation costs $(\bar{\varphi}=0)$, appendix $\mathrm{F}$ shows that the difference in expected returns on these claims can be approximated as

$$
\log \mathbb{E}_{t}\left[R_{H, t+1}^{(1)}\right]-\log \mathbb{E}_{t}\left[R_{L, t+1}^{(1)}\right]=-\left(\theta_{p}-\eta\right) \operatorname{cov}_{t}\left(m_{t, t+1}, p_{H, t+1}-p_{L, t+1}\right),
$$

where $p_{I, t}$ is the product $(\log )$ price for sector $I$. Differences in expected returns on sectoral profit claims are driven by the dynamics of the relative price $p_{H, t}-p_{L, t}$, and the elasticities of substitution $\eta$ for goods across sectors and $\theta_{p}$ for goods within each sector.

The difference in returns on profit claims is the result of the difference in output (output effect) and the difference in markups (markup effect) across the two sectors. In the model, a negative productivity shock increases product prices to compensate for high marginal costs given the wage rigidity. The price of good $H$ is lower than the price of good $L$ due to greater price rigidities in sector $H$. The output effect is then a higher demand for sector $H$ output in states of high marginal utility. It makes a claim on output $L$ riskier than a claim on output $H$, and increases the expected return of the sector $L$ claim relative to the sector $H$ claim. The output effect depends on the elasticity of substitution between the two goods, $\eta$. On the other hand, the negative relative price $\left(p_{H, t}<p_{L, t}\right)$ implies that the markup of

\footnotetext{
${ }^{19}$ We use a negative $\imath_{x}$ only to obtain an increase of $10 \%$ in output gap volatility. A negative response to the output, however, is not empirically supported.

${ }^{20}$ Additional details of the model extension can be provided by the authors under request.
} 
sector $H$ is smaller than that of sector $L$. This markup effect makes a claim on profits $H$ riskier than a claim on profits $L$, and increases the expected return of the sector $L$ claim relative to sector $H$. The markup effect depends on the elasticity of substitution among the differentiated goods within each sector, $\theta_{p}$. As a result, the net effect on expected returns on sectoral profit claims depends on the difference in elasticities within and across sectors. ${ }^{21}$

To explore the difference in expected returns quantitatively, we set $\alpha_{p_{H}}=0.8$ and $\alpha_{p_{L}}=0$. This implies a mean and a standard deviation of price durations of 2.2 quarters and 2.13 quarters, respectively, which are consistent with Bils and Klenow (2004) evidence. Panel B of table 5 presents the expected returns of sectoral output and profit claims for model specifications with different values of $\eta$. The output effect dominates $\left(\mathbb{E}\left[R_{Y_{H}}-R_{Y_{L}}\right]<0\right.$ and $\left.\mathbb{E}\left[R_{D_{H}}-R_{D_{L}}\right]<0\right)$ if $\eta>\theta_{p}$, while the markup effect dominates $\left(\mathbb{E}\left[R_{D_{H}}-R_{D_{L}}\right]>0\right)$ if $\eta<\theta_{p}$. The two effects exactly offset each other if $\theta_{p}=\eta$. The table also shows that the differences in expected returns are only quantitatively important for significant differences between $\theta_{p}$ and $\eta$.

\section{Discussion}

The nominal rigidities explored in this paper have interesting qualitative and quantitative implications for asset returns. Qualitatively, nominal price and wage rigidities, in combination with permanent productivity shocks, generate procyclical mean-reverting variation in labor demand that increases the riskiness of output and profit claims. In addition, price rigidities, when combined with wage rigidities, generate procyclical production markups that increase the riskiness of profit claims relative to output claims. In the presence of rigidities, real asset returns become sensitive to the response to economic conditions in an interest rate policy rule, and policy shocks become a priced risk factor that affect asset return volatility. Differences in price rigidities translate into differences in expected returns across production sectors. Quantitatively, wage rigidities have larger effects on expected asset returns than price rigidities, mainly as a compensation for permanent productivity shocks. However, the equity premium is only a small fraction of its empirical counterpart and has a minor sensitivity to the specification of the interest rate policy rule.

How should we interpret the limited quantitative performance of the model? On one hand, it highlights a significant shortcoming of the traditional New Keynesian framework to capture asset pricing dynamics. It raises doubts on whether nominal rigidities can be an important driver of asset returns and an important channel of transmission of monetary policy through asset prices. On the other hand, the model results can be taken as a reference point for future model developments and empirical analysis.

The model can be extended in at least four dimensions. First, the model abstracts from capital accumulation and, therefore, ignores any potential effects of nominal rigidities on investment behavior. The joint study of investment dynamics, nominal rigidities, and asset prices merits further exploration. Second, the model does not incorporate shocks that are becoming standard in New Keynesian models such as price and wage markup shocks or investment specific technological shocks. These shocks are important in these models to reproduce some observed macroeconomic dynamics, and can become significant risk factors in asset returns. Third, we assume homogeneous wage rigidities within and across sectors. Heterogeneity in wage rigidities and imperfect labor mobility can be an additional source of differences in the cross section of asset returns. Fourth, we assume that financial markets are complete and frictionless. The effects of monetary policy and nominal rigidities on asset returns can be amplified by financial frictions such as the financial accelerator in Bernanke, Gertler and Gilchrist (1999), or under limited financial market participation as in Galí, López-Salido and Vallés Liberal (2004).

The model delivers predictions for the link between nominal rigidities and expected asset returns that can be tested empirically. All else equal, economies with higher wage or price rigidities should have higher expected excess returns on production claims than economies with lower wage or price rigidities.

\footnotetext{
${ }^{21}$ It is worth mentioning that in a model with perfectly flexible wages, differences in price rigidities have the opposite effect on the relative price, and then an opposite effect on expected returns. After a negative productivity shock, the price of the sector $H$ good is high relative to the price of the sector $L$ good.
} 
Different labor laws or different market power regulations around the world translate into differences in wage and price frictions, that can be a source of variation across international equity returns. Different pricing policies across firms and production sectors can be reflected in heterogeneity in their expected stock returns. This study is already being undertaken by Gorodnichenko and Weber (2013) with positive results. Finally, the model prediction that interest rate monetary policy rules with more weight on inflation relative to output stabilization imply higher expected stock returns can be tested in the data. 


\section{References}

Altig, David, Lawrence Christiano, Martin Eichenbaum and Jesper Linde. 2011. "Firm-Specific Capital, Nominal Rigidities and the Business Cycle." Review of Economic Dynamics 14(2):225-247.

Alvarez, Fernando and Urban J. Jermann. 2005. "Using Asset Prices to Measure the Persistence of the Marginal Utility of Wealth." Econometrica 73(6):1977-2016.

Bansal, Ravi and Amir Yaron. 2004. "Long Run Risks: A Potential Resolution to Asset Pricing Puzzles." Journal of Finance 59.

Barattieri, Alessandro, Susanto Basu and Peter Gottschalk. 2014. "Some Evidence on the Importance of Sticky Wages." American Economic Journal: Macroeconomics 6(1):70-101.

Barsky, Robert B., Miles S. Kimball, F. Thomas Juster and Matthew D. Shapiro. 1997. "Preference Parameters and Behavioral Heterogeneity: An Experimental Approach in the Health and Retirement Study." The Quarterly Journal of Economics 112(2):537-79.

Bekaert, Geert, Seonghoon Cho and Antonio Moreno. 2010. "New Keynesian Macroeconomics and the Term Structure." Journal of Money, Credit and Banking 42(1):33-62.

Bernanke, Ben S. and Kenneth N. Kuttner. 2005. "What Explains the Stock Market's Reaction to Federal Reserve Policy?" Journal of Finance 60(3):1221-1257.

Bernanke, Ben S., Mark Gertler and Simon Gilchrist. 1999. The financial accelerator in a quantitative business cycle framework. In Handbook of Macroeconomics, ed. J. B. Taylor and M. Woodford. Vol. 1 of Handbook of Macroeconomics Elsevier chapter 21, pp. 1341-1393.

Bhamra, Harjoat, Adlai Fisher and Lars Alexander Kuehn. 2011. "Monetary Policy and Corporate Default." Journal of Monetary Economics 58(5):480-494.

Bils, Mark and Peter J. Klenow. 2004. "Some Evidence on the Importance of Sticky Prices." Journal of Political Economy 112(5):947-985.

Blinder, Alan S., Elie R.D. Canetti, David E. Lebow and Jeremy B. Rudd. 1998. Asking About Prices: A New Approach to Understanding Price Stickiness. First ed. New York: Russell Sage Foundation.

Boldrin, Michele, Lawrence J. Christiano and Jonas D. M. Fisher. 2001. "Habit Persistence, Asset Returns, and the Business Cycle." American Economic Review 91(1):149-166.

Calvo, Guillermo. 1983. "Staggered Prices in a Utility-Maximizing Framework." Journal of Monetary Economics 12:383-398.

Campbell, John Y. 1994. "Inspecting the mechanism: An analytical approach to the stochastic growth model." Journal of Monetary Economics 33(3):463-506.

Campbell, John Y. and John H. Cochrane. 1999. "By Force of Habit: A Consumption-Based Explanation of Aggregate Stock Market Behavior." Journal of Political Economy 107(2):205-251.

Christiano, Lawrence J., Martin Eichenbaum and Charles L. Evans. 2005. "Nominal Rigidities and the Dynamic Effects of a Shock to Monetary Policy." Journal of Political Economy 113(1):1-45.

Clarida, Richard, Jordi Galí and Mark Gertler. 2000. "Monetary Policy Rules and Macroeconomic Stability: Evidence and Some Theory." The Quarterly Journal of Economics pp. 147-180.

Cochrane, John. 2006. Financial Markets and the Real Economy. In International Library of Critical Writings in Financial Economics, ed. John Cochrane. Vol. 18 London: Edward Elgar. 
Croce, Mariano. 2014. "Long-Run Productivity Risk. A New Hope for Production-Based Asset Pricing?" Journal of Monetary Economics (forthcoming).

Epstein, Lawrence G. and Stanley E. Zin. 1989. "Substitution, Risk Aversion, and the Temporal Behavior of Consumption and Asset Returns: A Theoretical Framework." Econometrica 57:937-969.

Erceg, Christopher J., Dale W. Henderson and Andrew T. Levin. 2000. "Optimal monetary policy with staggered wage and price contracts." Journal of Monetary Economics 46(2):281-313.

Favilukis, Jack and Xiaoji Lin. 2013. "Wage Rigidity: A Quantitative Solution to Several Asset Pricing Puzzles." Working paper, London School of Economics and Ohio State University .

Galí, Jordi, Jose David López-Salido and Javier Vallés Liberal. 2004. "Rule-of-Thumb Consumers and the Design of Interest Rate Rules." Journal of Money, Credit and Banking 36(4):739-764.

Gorodnichenko, Yuriy and Michael Weber. 2013. Are Sticky Prices Costly? Evidence From The Stock Market. Working paper University of California, Berkeley.

Gourio, Francois. 2012. "Disaster Risk and Business Cycles." American Economic Review 102(6):273466.

Hall, Robert E. 1988. "Intertemporal Substitution in Consumption." Journal of Political Economy 96(2):339-57.

Kaltenbrunner, Georg and Lars A. Lochstoer. 2010. "Long-Run Risk through Consumption Smoothing." Review of Financial Studies 23(8):3190-3224.

Kydland, Finn E and Edward C. Prescott. 1982. "Time to Build and Aggregate Fluctuations." Econometrica 50(6):1345-70.

Lettau, Martin and Harald Uhlig. 2000. "Can Habit Formation be Reconciled with Business Cycle Facts?" Review of Economic Dynamics 3(1):79-99.

Lucca, David and Emanuel Moench. 2013. "The pre-FOMC Announcement Drift." Journal of Finance (forthcoming) .

Nakamura, Emi and Jón Steinsson. 2008. "Five Facts about Prices: A Reevaluation of Menu Cost Models." The Quarterly Journal of Economics 123(4):1415-1464.

Palomino, Francisco. 2012. "Bond Risk Premiums and Optimal Monetary Policy." Review of Economic Dynamics 15(1):19-40.

Piazzesi, Monika and Martin Schneider. 2007. Equilibrium Yield Curves. In NBER Macroeconomics Annual 2006, Volume 21. NBER Chapters National Bureau of Economic Research, Inc pp. 389-472.

Rigobon, Roberto and Brian Sack. 2004. "The Impact of Monetary Policy on Asset Prices." Journal of Monetary Economics 51(8):1553-1575.

Rudebusch, Glenn D. and Eric T. Swanson. 2012. "The Bond Premium in a DSGE Model with Long-Run Real and Nominal Risks." American Economic Journal: Macroeconomics 4(1):105-43.

Rudebusch, Glenn and Eric Swanson. 2008. "Examining the Bond Premium Puzzle with a DSGE Model." Journal of Monetary Economics 55:111-126.

Schmitt-Grohe, Stephanie and Martin Uribe. 2007. "Optimal Inflation Stabilization in a Medium-Scale Macroeconomic Model." Monetary Policy under Inflation Targeting 11(5):125-186.

Smets, Frank and Rafael Wouters. 2007. "Shocks and Frictions in US Business Cycles: a Bayesian DSGE Approach." American Economic Review 97(3):586-606. 
Swanson, Eric T. 2012. "Risk Aversion and the Labor Margin in Dynamic Equilibrium Models." American Economic Review .

Tallarini, Thomas D. 2000. "Risk-Sensitive Real Business Cycles." Journal of Monetary Economics 45(3):507-532.

Taylor, John B. 1993. "Discretion versus Policy Rules in Practice." Carnegie-Rochester Conference Series on Public Policy 39(1):195-214.

Thorbecke, Willem. 1997. "On Stock Market Returns and Monetary Policy." Journal of Finance $52(2): 635-54$.

Uhlig, Harald. 2007. "Explaining Asset Prices with External Habits and Wage Rigidities in a DSGE Model." American Economic Review 97(2):239-243.

Vissing-Jorgensen, Annette. 2002. "Limited Asset Market Participation and the Elasticity of Intertemporal Substitution." Journal of Political Economy 110(4):825-853.

Vissing-Jorgensen, Annette and Orazio P. Attanasio. 2003. "Stock-Market Participation, Intertemporal Substitution, and Risk-Aversion." American Economic Review 93(2):383-391.

Woodford, Michael. 2003. Interest and Prices. New Jersey: Princeton University Press. 
Table 1: Baseline Parameter Values.

The table contains the parameter values for the baseline calibration. The model is calibrated at quarterly frequency. The average productivity growth and volatilities are presented in per cent per quarter.

\begin{tabular}{llr}
\hline \hline Parameter & Description & Value \\
\hline Preferences & & \\
$\beta$ & Subjective discount factor & 1.0054 \\
$\psi$ & Inverse of elasticity of intertemporal substitution* & 6.5 \\
$\gamma$ & Risk aversion parameter & 84.5 \\
$\omega$ & Inverse of Frisch labor elasticity & 0.35 \\
\hline Rigidities and & Monopolistic Competition & 6 \\
$\theta_{p}$ & Elasticity of substitution of differentiated goods & 21 \\
$\theta_{w}$ & Elasticity of substitution of labor types & 0.63 \\
$\alpha_{p}$ & Price rigidity parameter & 0.78 \\
$\alpha_{w}$ & Wage rigidity parameter & \\
\hline Interest Rate Policy Rule & 0.63 \\
$\rho$ & Interest-rate smoothing coefficient in policy rule \\
$\bar{\imath}$ & Constant in the policy rule & 0.029 \\
$\imath_{\pi}$ & Response to inflation in the policy rule & 1.5 \\
$\imath_{x}$ & Response to output gap in the policy rule & 0.125 \\
$\phi_{u}$ & Autocorrelation of policy shock & 0.564 \\
$\sigma_{u}$ & Conditional volatility of policy shock & 0.151 \\
\hline Productivity & & \\
$\bar{\varphi}$ & Fixed production cost & 0.1472 \\
$g_{a}$ & Average productivity growth & 0.4695 \\
$\phi_{a}$ & Autocorrelation of permanent productivity shock & 0.391 \\
$\sigma_{a}$ & Conditional volatility of permanent productivity shock & 0.202 \\
$\phi_{z}$ & Autocorrelation of transitory productivity shock & 0.985 \\
$\sigma_{z}$ & Conditional volatility of permanent productivity shock & 0.102 \\
\hline
\end{tabular}

* This is elasticity of the utility aggregator of consumption and labor. 
Table 2: Data and Model Volatility.

The table contains the total volatility of macroeconomic variables and the volatility explained by the model shocks in the data and the model. The baseline parameter values are presented in table 1 . The variance decomposition is obtained from Altig et al. (2011). Columns labeled "Prod." refer to aggregate productivity shocks (permanent and transitory). The column labeled "Perm." refers to permanent productivity shocks. The column labeled "Trans." refers to transitory productivity shocks. The row labeled $\hat{c}_{t}$ refers to de-trended log consumption. Volatilities are measured in per cent per quarter. The sign "-" in the data columns indicates that the statistic is not available.

\begin{tabular}{|c|c|c|c|c|c|c|c|}
\hline \multicolumn{8}{|c|}{ Panel A: Macroeconomic moments } \\
\hline & Total & \multicolumn{6}{|c|}{ Volatility explained by the shocks } \\
\hline & volatility & \multicolumn{2}{|c|}{ Data } & \multicolumn{4}{|c|}{ Model } \\
\hline & Data (1982-2008) & Policy & Prod. & Policy & Prod. & Perm. & Trans. \\
\hline$i_{t}$ & 0.65 & 0.24 & 0.09 & 0.24 & 0.09 & 0.07 & 0.06 \\
\hline$\pi_{t}$ & 0.34 & 0.08 & 0.12 & 0.08 & 0.09 & 0.08 & 0.05 \\
\hline$\hat{c}_{t}$ & 0.76 & 0.17 & 0.22 & 0.17 & 0.22 & 0.17 & 0.14 \\
\hline$\Delta c_{t}$ & 0.37 & - & - & 0.12 & 0.35 & 0.35 & 0.03 \\
\hline \multicolumn{8}{|c|}{ Panel B: Asset pricing moments } \\
\hline \multirow[b]{2}{*}{ Sharpe ratio $\left(S R_{D}\right)$} & Data (1982-2008) & \multirow{2}{*}{\multicolumn{2}{|c|}{$\begin{array}{c}\text { Model } \\
0.215\end{array}$}} & & & & \\
\hline & 0.215 & & & & & & \\
\hline
\end{tabular}


Table 3: Model Summary Statistics. The Effect of Different Shocks.

The table contains statistics for the model baseline calibration and the contribution of each model shock to the results. The baseline parameter values are presented in table 1. "Baseline" indicates an economy with both price and wage rigidities. "Only $A^{p}$ " indicates only permanent productivity shocks $\left(\sigma_{z}=\sigma_{u}=0\right)$. "Only $Z$ " indicates only transitory productivity shocks $\left(\sigma_{a}=\sigma_{u}=0\right)$. "Only $u$ " indicates only policy shocks $\left(\sigma_{a}=\sigma_{z}=0\right)$. De-trended $\log$ consumption is denoted by $\hat{c}_{t}$. Excess returns and the Sharpe ratio for asset $b$ are $X R_{b, t}=R_{b, t+1}-R_{f, t}$, and $S R_{b}=\frac{\mathbb{E}\left[X R_{b, t}\right]}{\sigma\left(X R_{b, t}\right)}$, respectively. Volatilities and returns are measured in per cent per quarter. The sign "-" in the data column indicates that the statistic is not available.

\begin{tabular}{|c|c|c|c|c|c|}
\hline & Data & $\begin{array}{c}(1) \\
\text { Baseline }\end{array}$ & $\begin{array}{c}(2) \\
\text { Only } A^{p}\end{array}$ & $\begin{array}{c}(3) \\
\text { Only } Z\end{array}$ & $\begin{array}{c}(4) \\
\text { Only } u\end{array}$ \\
\hline \multicolumn{6}{|c|}{ Panel A: Macroeconomic variables } \\
\hline$\sigma(\pi)$ & 0.34 & 0.12 & 0.08 & 0.05 & 0.08 \\
\hline$\sigma(\hat{c})$ & 0.76 & 0.27 & 0.17 & 0.14 & 0.17 \\
\hline$\sigma(i)$ & 0.65 & 0.26 & 0.07 & 0.06 & 0.24 \\
\hline$\sigma\left(\log \mu_{p}\right)$ & - & 0.17 & 0.13 & 0.08 & 0.07 \\
\hline$\sigma(\Delta c)$ & 0.37 & 0.37 & 0.35 & 0.03 & 0.12 \\
\hline$\sigma(\Delta d)$ & 8.10 & 8.10 & 6.74 & 4.39 & 0.97 \\
\hline$\rho\left(\Delta c, \log \mu_{p}\right)$ & - & 0.47 & 0.60 & 0.77 & 0.03 \\
\hline$\rho\left(\Delta c, n^{d}\right)$ & 0.10 & 0.30 & 0.87 & -0.06 & 0.37 \\
\hline \multicolumn{6}{|c|}{ Panel B: Asset returns } \\
\hline $\mathbb{E}[i]$ & 1.30 & 1.30 & 1.31 & 2.53 & 2.54 \\
\hline $\mathbb{E}\left[X R_{Y, t+1}\right]$ & - & 0.12 & 0.12 & 0.002 & 0.004 \\
\hline $\mathbb{E}\left[X R_{D, t+1}\right]$ & 1.78 & 0.24 & 0.23 & 0.006 & 0.003 \\
\hline$\sigma\left(R_{Y}\right)$ & - & 0.85 & 0.43 & 0.12 & 0.72 \\
\hline$\sigma\left(R_{D}\right)$ & 8.30 & 1.10 & 0.82 & 0.47 & 0.56 \\
\hline$S R_{Y}$ & - & 0.15 & 0.28 & 0.01 & 0.01 \\
\hline$S R_{D}$ & 0.22 & 0.22 & 0.28 & 0.01 & 0.01 \\
\hline
\end{tabular}


Table 4: Model Summary Statistics. The Effect of Different Rigidities.

The table contains statistics for the model baseline calibration and the contribution of each nominal rigidity to the results. The baseline parameter values are presented in table 1, except for the fixed cost parameter $\bar{\varphi}$. All model specifications assume $\bar{\varphi}=0$. "Baseline" indicates the baseline economy with both price and wage rigidities. "No Rig." indicates no price and wage rigidities $\left(\alpha_{p}=\alpha_{w}=0\right)$. "Only WR" indicates no price rigidities $\left(\alpha_{p}=0\right)$. "Only PR" indicates no wage rigidities $\left(\alpha_{w}=0\right)$. De-trended $\log$ consumption is denoted by $\hat{c}_{t}$. Excess returns and the Sharpe ratio for asset $b$ are $X R_{b, t}=R_{b, t+1}-R_{f, t}$, and $S R_{b}=\frac{\mathbb{E}\left[X R_{b, t}\right]}{\sigma\left(X R_{b, t}\right)}$, respectively. Panel $\mathrm{C}$ reports the conditional standard deviations of the pricing kernel $m$, its short-run component $m^{S R}$, and its long-run component $m^{S R}$, as well as the conditional correlation between the short-run and the long-run components. Volatilities and returns are measured in per cent per quarter. The sign "-" in the data column indicates that the statistic is not available.

\begin{tabular}{|c|c|c|c|c|c|}
\hline & Data & $\begin{array}{c}(1) \\
\text { Baseline }\end{array}$ & $\begin{array}{c}(2) \\
\text { No Rig. } \\
\end{array}$ & $\begin{array}{c}(3) \\
\text { Only WR }\end{array}$ & $\begin{array}{c}(4) \\
\text { Only PR }\end{array}$ \\
\hline \multicolumn{6}{|c|}{ Panel A: Macroeconomic variables } \\
\hline$\sigma(\pi)$ & 0.34 & 0.12 & 0.86 & 0.21 & 0.33 \\
\hline$\sigma(\hat{c})$ & 0.76 & 0.27 & 0.12 & 0.28 & 0.17 \\
\hline$\sigma(i)$ & 0.65 & 0.26 & 0.42 & 0.26 & 0.14 \\
\hline$\sigma\left(\log \mu_{p}\right)$ & - & 0.17 & 0.00 & 0.00 & 0.84 \\
\hline$\sigma(\Delta c)$ & 0.37 & 0.37 & 0.22 & 0.38 & 0.30 \\
\hline$\sigma(\Delta d)$ & 8.10 & 0.69 & 0.02 & 0.22 & 4.48 \\
\hline$\rho\left(\Delta c, \log \mu_{p}\right)$ & - & 0.47 & 0.00 & 0.00 & -0.79 \\
\hline$\rho\left(\Delta c, n^{d}\right)$ & 0.10 & 0.30 & -0.01 & 0.33 & 0.19 \\
\hline \multicolumn{6}{|c|}{ Panel B: Asset returns } \\
\hline $\mathbb{E}[i]$ & 1.30 & 1.30 & 1.64 & 1.28 & 1.55 \\
\hline $\mathbb{E}\left[X R_{Y, t+1}\right]$ & - & 0.12 & -0.13 & 0.15 & 0.03 \\
\hline $\mathbb{E}\left[X R_{D, t+1}\right]$ & 1.78 & 0.13 & -0.13 & 0.15 & 0.00 \\
\hline$\sigma\left(R_{Y}\right)$ & - & 0.85 & 0.51 & 0.89 & 0.42 \\
\hline$\sigma\left(R_{D}\right)$ & 8.30 & 0.85 & 0.51 & 0.89 & 0.30 \\
\hline$S R_{Y}$ & - & 0.15 & -0.26 & 0.17 & 0.06 \\
\hline$S R_{D}$ & 0.22 & 0.16 & -0.26 & 0.17 & 0.02 \\
\hline \multicolumn{6}{|c|}{ Panel C: Pricing kernel decomposition } \\
\hline$\sigma(m)$ & - & 0.30 & 0.30 & 0.06 & 0.00 \\
\hline$\sigma\left(m^{S R}\right)$ & - & 0.21 & 0.19 & 0.08 & 0.02 \\
\hline$\sigma\left(m^{L R}\right)$ & - & 0.12 & 0.11 & 0.02 & 0.02 \\
\hline $\operatorname{corr}\left(m^{S R}, m^{L R}\right)$ & - & 0.64 & 0.80 & -1.00 & -1.00 \\
\hline $\operatorname{corr}\left(m, m^{L R}\right)$ & - & 0.82 & 0.94 & -1.00 & -0.98 \\
\hline
\end{tabular}


Table 5: Additional Model Implications.

The table contains summary statistics for different specifications of the monetary policy rule in panel A, and for a model extension for two sectors with different price rigidities in panel B.

Panel A: The interest rate rule is $i_{t}=\rho i_{t-1}+(1-\rho)\left(\bar{\imath}+\imath_{\pi} \pi_{t}+\imath_{x} x_{t}\right)+u_{t}$. The baseline parameter values are presented in table 1. "Baseline" indicates an economy with both price and wage rigidities. Columns (2), (3) and (4) report model statistics for individual changes in parameter values for $\imath_{\pi}, \imath_{x}$, and $\rho$, respectively. The calibration in column (4) also adjusts the $\imath_{\pi}$ and $\imath_{x}$ coefficients such that $(1-\rho) \imath_{\pi}$ and $(1-\rho) \imath_{x}$ stay at their baseline levels. Expected excess returns and Sharpe ratios for asset $b$ are $X R_{b, t}=R_{b, t+1}-R_{f, t}$, and $S R_{b}=\frac{\mathbb{E}\left[X R_{b, t}\right]}{\sigma\left(X R_{b, t}\right)}$, respectively. A variable with the sign "**" indicates a statistic for a model with $\bar{\varphi}=0$. Figures in parenthesis are percentage changes with respect to the baseline calibration. Volatilities and returns are reported in basis points per quarter.

Panel B: The baseline parameter values are presented in table 1 , except for $\beta=1.0063$ and $\gamma=0.79$. The sectoral price rigidity parameters are $\alpha_{p_{H}}=0.8$ and $\alpha_{p_{L}}=0$. Excess returns are $X R_{b, t}=R_{b, t+1}-R_{f, t}$. Returns are measured in per cent per quarter.

Panel A: Different Reaction Coefficients in the Interest Rate Policy Rule

\begin{tabular}{|c|c|c|c|c|c|c|c|}
\hline \multirow{6}{*}{$\begin{array}{l}\sigma(\pi) \\
\sigma(x) \\
\sigma(\Delta c) \\
\sigma(\Delta d) \\
\sigma(\Delta d)^{*}\end{array}$} & \multirow{2}{*}{$\begin{array}{c}(1) \\
\text { Baseline } \\
12.12\end{array}$} & \multicolumn{2}{|c|}{$\begin{array}{c}(2) \\
\imath_{\pi}=1.89\end{array}$} & \multicolumn{2}{|c|}{$\begin{array}{c}(3) \\
\imath_{x}=-0.16\end{array}$} & \multicolumn{2}{|c|}{$\begin{array}{c}(4) \\
\rho=0.712\end{array}$} \\
\hline & & 10.91 & $(-9.96)$ & 12.21 & $(0.78)$ & 12.65 & (4.44) \\
\hline & 23.71 & 23.54 & $(-0.72)$ & 26.09 & $(10.03)$ & 26.10 & $(10.05)$ \\
\hline & 36.92 & 37.34 & $(1.15)$ & 38.41 & $(4.05)$ & 37.83 & $(2.46)$ \\
\hline & 809.92 & 803.09 & $(-0.84)$ & 787.97 & $(-2.71)$ & 806.15 & $(-0.47)$ \\
\hline & 69.41 & 68.92 & $(-0.7)$ & 67.90 & $(-2.18)$ & 69.16 & $(-0.36)$ \\
\hline $\mathbb{E}\left[X R_{Y, t+1}\right]$ & 12.41 & 13.63 & $(9.82)$ & 14.46 & (16.48) & 13.20 & $(6.38)$ \\
\hline $\mathbb{E}\left[X R_{D, t+1}\right]$ & 23.65 & 24.47 & $(3.47)$ & 24.58 & $(3.94)$ & 23.85 & $(0.83)$ \\
\hline $\mathbb{E}\left[X R_{D, t+1}\right]^{*}$ & 13.21 & 14.38 & $(8.91)$ & 15.14 & (14.68) & 13.94 & $(5.52)$ \\
\hline$S R_{Y}$ & 0.15 & 0.16 & (11.46) & 0.15 & $(3.71)$ & 0.14 & $(-3.57)$ \\
\hline$S R_{D}$ & 0.22 & 0.22 & $(2.93)$ & 0.22 & $(0.47)$ & 0.21 & $(-1.05)$ \\
\hline$S R_{D}^{*}$ & 0.16 & 0.17 & (10.09) & 0.16 & $(2.66)$ & 0.15 & $(-3.67)$ \\
\hline
\end{tabular}

Panel B: Sectoral Expected Returns

\begin{tabular}{lccc}
\hline \hline & $\theta_{p}>\eta=2$ & $\theta_{p}=\eta=6$ & $\theta_{p}<\eta=20$ \\
\hline $\mathbb{E}\left[X R_{Y, t+1}\right]$ & 0.123 & 0.123 & 0.123 \\
$\mathbb{E}\left[X R_{Y, H, t+1}\right]$ & 0.122 & 0.115 & 0.093 \\
$\mathbb{E}\left[X R_{Y, L, t+1}\right]$ & 0.125 & 0.131 & 0.153 \\
$\mathbb{E}\left[X R_{D, t+1}\right]$ & 0.271 & 0.271 & 0.271 \\
$\mathbb{E}\left[X R_{D, H, t+1}\right]$ & 0.371 & 0.272 & -0.072 \\
$\mathbb{E}\left[X R_{D, L, t+1}\right]$ & 0.171 & 0.270 & 0.622 \\
\hline
\end{tabular}




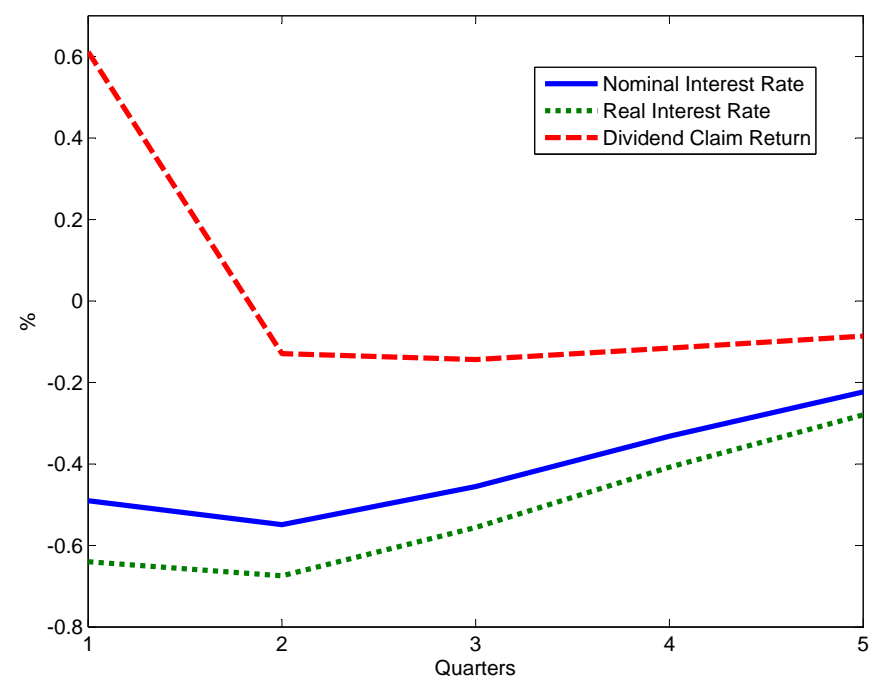

Figure 1: Impulse responses to an expansionary monetary policy shock for the one-period nominal and real interest rates, $i_{t}$ and $r_{t}$, respectively, and the return on the dividend claim, $R_{d, t}$. The parameter values are presented in table 1 . The interest rates are annualized. 